\title{
Six Sigma Project Critical Success Factor Prioritization Using MADM Technique
}

\author{
Hessam Zandhessami ${ }^{1}$, Arezoo Rahgozar ${ }^{2}$ \\ 1 Professor Assistant of Department of Industrial Management, Qazvin Branch, Islamic Azad \\ University, Qazvin, Iran \\ ${ }^{2}$ Department of Industrial Management, Qazvin Branch, Islamic Azad University, Qazvin, Iran
}

\begin{tabular}{ll} 
ARTICLE INFO & ABSTRACT \\
\cline { 1 - 2 } $\begin{array}{l}\text { Keywords: } \\
\text { Six Sigma }\end{array}$ Modeling & $\begin{array}{l}\text { Purpose-The purpose of this research paper is to study the enablers of Six } \\
\text { Sigma and to establish a relationship among them using DEMATEL. } \\
\text { Design/methodology/approach- The research paper presents a blend of } \\
\text { theoretical framework and practical applications. In the paper, 11 enablers } \\
\text { of Six Sigma are identified from literature survey. The required data was } \\
\text { collected from five specialists, factory managers and maintenance } \\
\text { managers who have worked in Six Sigma fields. }\end{array}$ \\
Paper type & $\begin{array}{l}\text { Findings-Variable F8 (Committed workforce) is known as the influential } \\
\text { and Variable F1 (ETML) is known as the effective. Other elements can be } \\
\text { claimed to have a partial influence. } \\
\text { Originality/value-knowing the key enablers and relationship among } \\
\text { them can help organizations to develop Six Sigma competences. It is one } \\
\text { of the foremost attempts to model enablers of Six Sigma. The paper } \\
\text { provides useful insights to the Six Sigma implementers, consultants, and } \\
\text { researchers. }\end{array}$ \\
\hline
\end{tabular}

\section{Introduction}

Six Sigma was introduced by Motorola in 1986 and was initially adopted by organizations in the manufacturing sector including prominent examples such as the Six Sigma roll-out at general Electric in the mid-1990s. Since then it has spread tremendously towards the end of the twentieth century and has been used heavily in the area of manufacturing. (Heckl, 2010).Six Sigma is a total quality system to identify tools, methods and best practices for generating innovation and driving revenue growth (Eng, 2010). The Six Sigma improvement methodology has received considerable attention recently, not only in the statistical and quality literature but also within the general business literature.Word-class transnational enterprises like Motorola, GE, and GITI Group achieved great performance in customer satisfaction by employing Six Sigma method (Cheng, 2008).

Six Sigma can be considered both as a business strategy and as a science that aims at reducing manufacturing and service costs, and creating significant improvements in customer satisfaction and bottom-line savings through combining statistical and business process methodologies into an integrated model of process, product and service improvement (Thomas\& et al, 2008).Six Sigma is one of the most recent quality management innovations which many organizations have adopted, with the intent to significantly improve performance and customer service. Six Sigma initiatives are closely related to total quality management (TQM) initiatives (Braunscheidel \& et al, 2011). It is named after a process that has six standard deviations on each side of specification window (Ashishsoti\& et al, 2009). 
The discipline of Six Sigma is particularly good for organization seeking both bottom-line improvement and defect reduction (Ashishsoti \& et al, 2009). There are critical success factors that are critical to the success of any organization, in the sense that, if objectives associated with the factors are not achieved, the organization will fail--perhaps catastrophically (Ashishsoti \& et al, 2009). These success factors are the key parameters that make Six Sigma applications fruitful for an organization. Success parameters are foundational, operational or sustainability parameters; these are useful from inception to the maturity of Six Sigma system (Ashishsoti \& et al, 2009).

This paper focuses on the following two objectives: 1) Identifying the enablers of Six Sigma. 2) Modeling the enablers of Six Sigma using decision making trial and evaluation laboratory (DEMATEl).

\section{Literature review}

\section{Six Sigma}

Six Sigma refers to a series of processes of defining problems from the "perspective of customers", measuring the current state with objective indices, analyzing the causes and the validity of the problems in a scientific and systematic manner, applying improvement measures with practical features, and controlling the situation. DMAIC (see Figure 1) represents the five stages of Six Sigma execution (Kim, 2007; Raisinghani \& et al., 2005). DMAIC forms the most fundamental problem-solving stage in Six Sigma and focuses on increasing the quality of the current process (Kim, 2010).

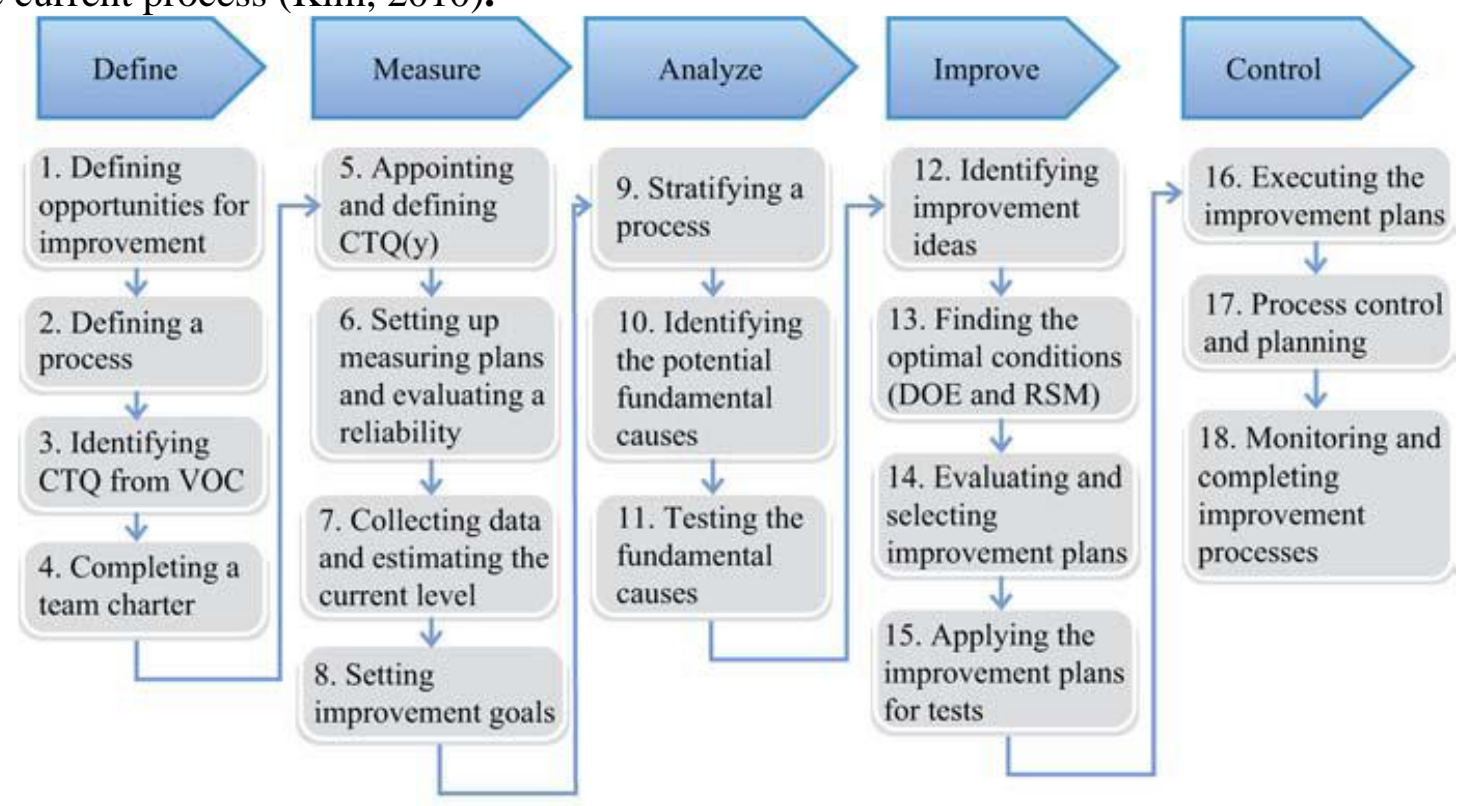

Notes: $\mathrm{CTQ}=$ Critical to quality, $\mathrm{VOC}=$ Voice of the customer, $\mathrm{DOE}=$ Design of experiments, $\mathrm{RSM}=$ Response surface methodology

Figure 1: problem-solving stage in Six Sigma (Kim, 2010)

\section{Enablers of Six Sigma (critical success factors)}

Brother ton and Shaw (1996) define critical success factors (CSFs) as the essential things that must be achieved by the company to identify which areas will produce the greatest "competitive leverages". They emphasize that CSFs are not major objectives, but are the actions and processes that can be controlled by the management to achieve the organization`s goals. Waxer (2004) proposes four major requirements for successful Six Sigma implementation within any organization: 1) Management team buy-in and support; 2) Education and training; 3) Resource commitment; 4) Link to compensation (Jeyaraman, KeeTeo, 2010). In this research 
Table1: instrument developed to identify the CSFs of Six Sigma (Antony\& et al, 2 006).

\begin{tabular}{|l|l|}
\hline \multicolumn{1}{|c|}{ Instrument } & Items \\
\hline Management commitment and involvement & (five items) \\
\hline Company-wide commitment & (five items) \\
\hline Cultural change & (four items) \\
\hline Linking Six Sigma to business strategy & (four items) \\
\hline Integrating Six Sigma with the financial infrastructure & (three items) \\
\hline Organizational infrastructure & (three items) \\
\hline Training and education & (four items) \\
\hline Incentive program & (three items) \\
\hline Customer focus & (four items) \\
\hline Understanding the DMAIC methodology & (four items) \\
\hline Project management skills & (three items) \\
\hline Project tracking and reviews & (three items) \\
\hline Project prioritization and selection & (six items) \\
\hline
\end{tabular}

Most of the bibliography about Six Sigma describes critical success factors for the "kick-off" and deployment, but giving less attention to factors affecting the maintenance or sustainability of the initiative. One reason for this emphasis could be the implicit belief that as the company develops a solid infrastructure through "rotation" of Block Belts and a strong linkage with business strategies, there will always be new opportunities for projects with financial justification appropriate for the DMAIC process. (Firka, 2010). Six Sigma success factors can also be found in other aspects. Although few case studies have been conducted at libraries, there have been numerous reports of Six Sigma success factors published by for-profit organizations. There are common factors that reflect the characteristics of Six Sigma. An example would be the claim that although employee participation is important, the top-down approach makes the drive and leadership of managers in positions of high authority more important than anything (Kim, 2010). CSFs should be all adopted whenever possible, and embedded into the culture of an organization.

Some CSFs are related to cultural acceptance (CA) by the work force whilst other CSFs are more concerned with the technical quality (TQ) of an initiative. These findings imply that it is equally important for an organization to use an even balance of both types of CSFs within a program if it is going to be considered a complete success rather than just a partial success (Ben clegg, Chris Ress, Mike Titchen, 2009).

Studies done by various researchers, addressing critical success factors/ essentials/ foundation blocks for Six Sigma were reviewed. They were reviewed with an intent to find out all the factors related to the success of Six Sigma; these factors are called foundation blocks/essentials/requirements/enablers or success factors. In this study, we take 11 enablers of Soti and et al (2009) research. They came up with the following list of enablers:

Table 2: critical success factors (Soti \& et al, 2009)

\begin{tabular}{|c|l|}
\hline Code & \multicolumn{1}{|c|}{ Enablers/CSF } \\
\hline E1 & Effective top management leadership (ETML) role \\
\hline E2 & Quality maturity level (QMLO) of the organization \\
\hline E3 & Availability of funds \\
\hline E4 & Organizational infrastructure \\
\hline E5 & Availability of expertise training (AET) \\
\hline
\end{tabular}




\begin{tabular}{|c|l|}
\hline E6 & Statistical thinking \\
\hline E7 & Employees' adaptability and flexibility towards learning (EAFL) \\
\hline E8 & Committed workforce \\
\hline E9 & Reliable data gathering and retrieval system \\
\hline E10 & Technical competence (TC) \\
\hline E11 & Organizational culture \\
\hline
\end{tabular}

\section{Research method}

In this section, the steps of work performance are explained (Figure 1). After identifying and extraction enablers of Six Sigma, a questionnaire was planned to determine the interdependence between the factors. Finally, 11 selected enablers are used to obtain the hierarchy among the enablers. The required data was collected from five specialists, factory managers and maintenance managers who have worked in Six Sigma fields. Relationships between 11 variables are measured in this study with DEMATEL technique.

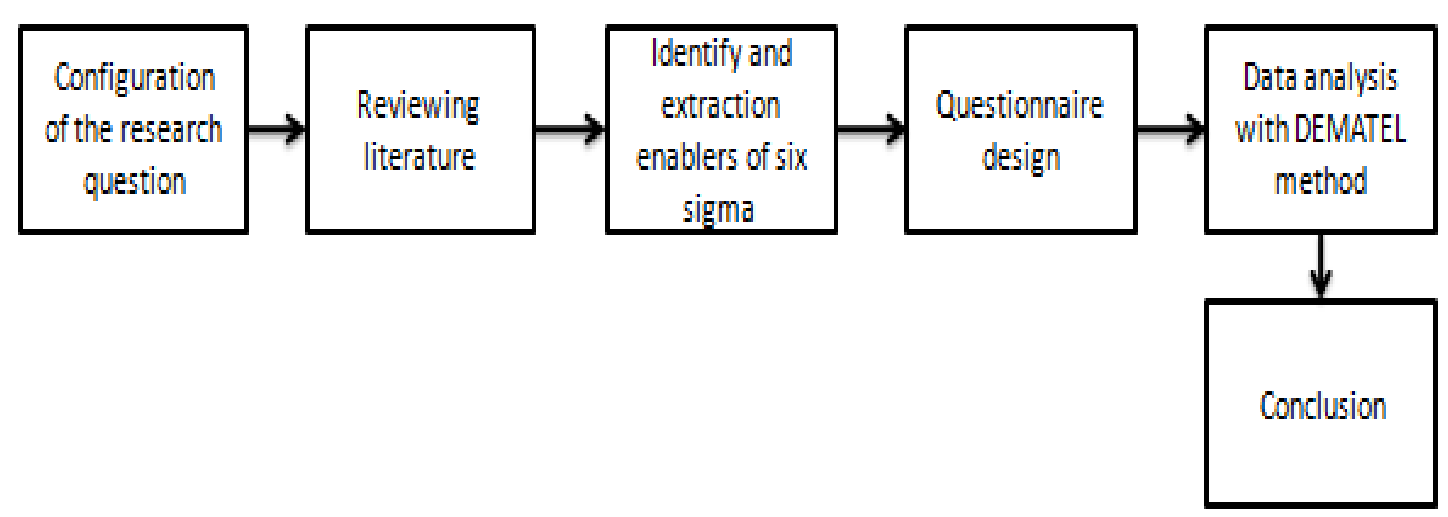

Figure 2: Research method

\section{Methodology}

DEMATEL was developed by the science and human affairs program of the Battelle Memorial Institute of Geneva between 1972 and 1976 and it was used to solve the complicated and intertwined problem group (Amiri \& et al, 2010).

The DEMATEL method was developed: (1) to analyze complex "world problem" dealing mainly with interactive man-model techniques; and (2) to evaluate qualitative and factor-linked aspect of societal problems (Tzeng and Huang, 2011).

Its core is the calculation of indirect relations between variables based on the assessment of the direct ones. By addressing the nature of relations between variables the DEMATEL method allows, inter alia, the distinction of cause and effect variables (Hiete \& et al, 2011).

The DEMATEL method is a comprehensive method for making and analyzing a structured model involving causal relationships between complex factors. Using this method illustrates the interrelations among criteria and applied matrices and digraphs for visualizing the structure of complicated causal relationships. Hence the DEMATEL methods can be subsumed under the cause and effect groups to assist in making effective decisions (Fekri\& et al, 2008).

DEMATEL was developed with the belief that the pioneering and appropriate use of scientific research methods could improve understandings of a specific problematique (the cluster of intertwined problems) and help identify workable solutions through a network structure. This methodology, according to the concrete characteristics of objective affairs, can confirm the interdependence among the variables/criteria and restrict the relations that reflect characteristics with an essential system and development trend (Tzeng\& et al, 2009). 


\section{The proposed DEMATEL technique}

Definition 1 The pair-wise comparison scale may be designated as eleven levels, where the scores $0,1,2, \ldots, 10$ represent the range from 'no influence' to 'very high influence'.

Definition 2 The initial direct relation/influence matrix A is an $\mathrm{n} \times \mathrm{n}$ matrix obtained by pairwise comparisons, in terms of influences and directions between the determinants, in which aij is denoted as the degree to which the ith determinant affects the jth determinant.

$$
A=\left[\begin{array}{cccc}
a_{11} & a_{12} & \cdots & a_{1 n} \\
a_{21} & a_{22} & \cdots & a_{2 n} \\
\vdots & \vdots & & \vdots \vdots \\
a_{n 1} & a_{n 2} & \cdots & a_{n n}
\end{array}\right]
$$

Definition 3 The normalized direct relation/influence matrix $\mathrm{N}$ can be obtained through (1) and (2), in which all principal diagonal elements are equal to zero.

$N=Z A(1)$

$\mathrm{z}=\min \left\{1 / \max _{\mathrm{i}}^{\max } \quad \sum_{\mathrm{j}=1}^{\mathrm{n}} \mathrm{a}_{\mathrm{ij}}, 1 / \max _{\mathrm{j}}^{\operatorname{ma}} \sum_{\mathrm{i}=1}^{\mathrm{n}} \mathrm{a}_{\mathrm{ij}}\right\}, \mathrm{i}, \mathrm{j} \in\{1,2, \ldots, \mathrm{n}\}$.

In this case, $\mathrm{N}$ is called the normalized matrix. Since lime $\rightarrow \infty \mathrm{N} \varepsilon=[0]$.

Definition 4 Then, the total relationship matrix T can be obtained using (3), where I stands for the identity matrix. $T=N+N^{2}+\ldots+N^{\varepsilon}=N(1-N)(1-N)^{-1}$, (3) where $\varepsilon \rightarrow \infty$ and T is a total influence-related matrix; $\mathrm{N}$ is a direct influence matrix and $N=$ $\left[x_{i j}\right]_{n \times n ;}$ [Explanation]

$$
\begin{gathered}
\mathrm{T}=\mathrm{N}+\mathrm{N}^{2}+\mathrm{N}^{3}+\ldots+\mathrm{N}^{\varepsilon} \\
=\mathrm{N}\left(\mathrm{I}+\mathrm{N}+\mathrm{N}^{2}+\ldots+\mathrm{N}^{\varepsilon-1}\right)(1-\mathrm{N})(1-\mathrm{N})^{-1} \\
=\mathrm{N}(1-\mathrm{N})^{-1}(1-\mathrm{N})^{-1}
\end{gathered}
$$

$=\mathrm{N}(1-\mathrm{N})^{-1}$, when $\varepsilon \rightarrow \infty, \mathrm{N}^{\varepsilon}=[0]_{\mathrm{n} \times \mathrm{n}}$

Where $0 \leq \mathrm{x}_{\mathrm{ij}}<1,0<\sum_{\mathrm{j}=1}^{\mathrm{n}} \mathrm{x}_{\mathrm{ij}} \leq 1$ and $0<\sum_{\mathrm{i}=1}^{\mathrm{n}} \mathrm{x}_{\mathrm{ij}} \leq 1$, at least one row or column of summation is equal to 1 , but not all, then

$$
\lim _{\varepsilon \rightarrow \infty} N \varepsilon=[0]_{n \times n} .
$$

The $(i, j)$ element $t_{i j}$ of matrix $T$ denotes the direct and indirect influences of factor $i$ on factor j.

Definition 5 The row and column sums are separately denoted as $\mathrm{r}$ and $\mathrm{c}$ within the total relation matrix $\mathrm{T}$ through (4), (5), and (6).

$$
\begin{gathered}
T=\left[t_{i j}\right], \quad i, j \in\{1,2, \ldots, n\} \\
r=\left[r_{i}\right]_{n \times 1}=\left(\sum_{j=1}^{n} t_{i j}\right)_{n \times 1} \\
c=\left[c_{j}\right]_{n \times 1}=\left(\sum_{i=1}^{n} t_{i j}\right)_{1 \times n}
\end{gathered}
$$

Where the $r$ and $c$ vectors denote the sums of the rows and columns, respectively.

Definition 6 Suppose that ri displays the row sum of the ith row of matrix T. Then, ri is the sum of the influences dispatching from factor $i$ to the other factors, both directly and indirectly. Suppose that cj denotes the column sum of the $\mathrm{j}$ th column of matrix $\mathrm{T}$. Then, $\mathrm{cj}$ is the sum of the influences that factor $i$ is receiving from the other factors. Furthermore, when $i=j$ (i.e., the sum of the row sum and the column sum ( $\mathrm{ri}+\mathrm{ci}$ ) represents the index indicating the strength of the influence, both dispatching and receiving), ( $\mathrm{ri}+\mathrm{ci})$ is the degree of the central role that 
factor $\mathrm{i}$ plays in the problem. If (ri - ci) is positive, then factor $\mathrm{i}$ is primarily dispatching influence upon the strength of other factors; and if ( $\mathrm{ri}-\mathrm{ci}$ ) is negative, then factor i is primarily receiving influence from other factors (Huang et al, 2007; Liou et al, 2007; Tamura et al, 2002).

\section{Results}

As it was mentioned, 11 enablers of Six Sigma were identified from literature survey. Which are shown in table 3. The questionnaire was designed based on the DEMATEL model and distributed among experts. The following table shows the result of experts' opinion.

\section{Proposed model}

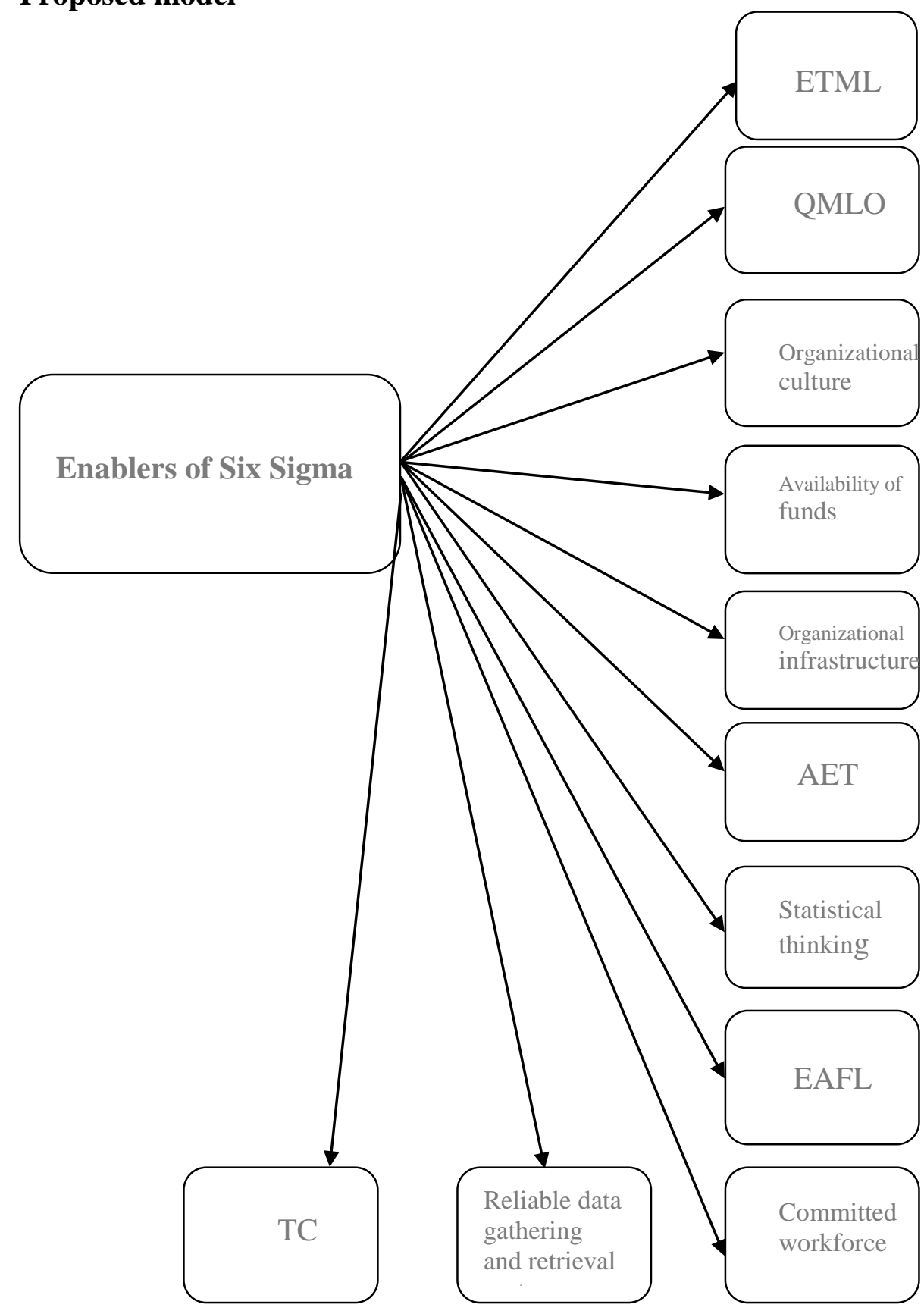

Figure 3: Proposed Model 
Table 3: The relative intensity of the direct relationship

\begin{tabular}{|c|c|c|c|c|c|c|c|c|c|c|c|}
\hline & F1 & F2 & F3 & F4 & F5 & F6 & F7 & F8 & F9 & F10 & F11 \\
\hline F1 & 0.00 & 0.10 & 0.12 & 0.12 & 0.09 & 0.07 & 0.09 & 0.12 & 0.07 & 0.08 & 0.10 \\
\hline F2 & 0.08 & 0.00 & 0.05 & 0.09 & 0.09 & 0.09 & 0.09 & 0.10 & 0.08 & 0.08 & 0.09 \\
\hline F3 & 0.11 & 0.07 & 0.00 & 0.07 & 0.10 & 0.05 & 0.06 & 0.08 & 0.06 & 0.08 & 0.06 \\
\hline F4 & 0.10 & 0.08 & 0.11 & 0.00 & 0.08 & 0.07 & 0.09 & 0.10 & 0.07 & 0.06 & 0.07 \\
\hline F5 & 0.11 & 0.11 & 0.07 & 0.06 & 0.00 & 0.10 & 0.10 & 0.10 & 0.07 & 0.09 & 0.07 \\
\hline F6 & 0.09 & 0.09 & 0.07 & 0.04 & 0.09 & 0.00 & 0.08 & 0.04 & 0.09 & 0.08 & 0.08 \\
\hline F7 & 0.10 & 0.10 & 0.05 & 0.09 & 0.08 & 0.07 & 0.00 & 0.08 & 0.05 & 0.09 & 0.09 \\
\hline F8 & 0.12 & 0.10 & 0.07 & 0.08 & 0.09 & 0.05 & 0.09 & 0.00 & 0.07 & 0.09 & 0.11 \\
\hline F9 & 0.08 & 0.05 & 0.09 & 0.08 & 0.06 & 0.11 & 0.06 & 0.05 & 0.00 & 0.05 & 0.07 \\
\hline F10 & 0.10 & 0.07 & 0.08 & 0.06 & 0.07 & 0.06 & 0.09 & 0.08 & 0.05 & 0.00 & 0.07 \\
\hline F11 & 0.10 & 0.10 & 0.07 & 0.07 & 0.10 & 0.09 & 0.10 & 0.07 & 0.09 & 0.06 & 0.00 \\
\hline
\end{tabular}

Table 4: The relative intensity of the indirect relationship

\begin{tabular}{|c|c|c|c|c|c|c|c|c|c|c|c|c|c|c|}
\hline & F1 & F2 & F3 & F4 & F5 & F6 & F7 & F8 & F9 & F10 & F11 & R & R+C & R-C \\
\hline F1 & 0.48 & 0.52 & 0.49 & 0.48 & 0.50 & 0.43 & 0.50 & 0.51 & 0.41 & 0.45 & 0.49 & 5.25 & 10.62 & -0.13 \\
\hline F2 & 0.49 & 0.38 & 0.39 & 0.41 & 0.45 & 0.41 & 0.45 & 0.45 & 0.38 & 0.41 & 0.43 & 4.65 & 9.46 & -0.17 \\
\hline F3 & 0.48 & 0.40 & 0.30 & 0.36 & 0.42 & 0.34 & 0.38 & 0.40 & 0.33 & 0.37 & 0.37 & 4.15 & 8.48 & -0.18 \\
\hline F4 & 0.51 & 0.45 & 0.43 & 0.33 & 0.44 & 0.39 & 0.44 & 0.45 & 0.37 & 0.38 & 0.41 & 4.59 & 8.85 & 0.33 \\
\hline F5 & 0.54 & 0.49 & 0.42 & 0.40 & 0.38 & 0.43 & 0.47 & 0.46 & 0.38 & 0.43 & 0.43 & 4.84 & 9.53 & 0.16 \\
\hline F6 & 0.46 & 0.42 & 0.37 & 0.34 & 0.41 & 0.29 & 0.40 & 0.36 & 0.36 & 0.37 & 0.39 & 4.15 & 8.35 & -0.05 \\
\hline F7 & 0.49 & 0.45 & 0.37 & 0.40 & 0.43 & 0.38 & 0.35 & 0.42 & 0.34 & 0.40 & 0.42 & 4.46 & 9.15 & -0.23 \\
\hline F8 & 0.54 & 0.48 & 0.42 & 0.42 & 0.46 & 0.39 & 0.46 & 0.73 & 0.81 & 0.43 & 0.46 & 5.61 & 10.55 & 0.67 \\
\hline F9 & 0.42 & 0.36 & 0.37 & 0.35 & 0.36 & 0.37 & 0.36 & 0.35 & 0.26 & 0.32 & 0.36 & 3.88 & 8.20 & -0.44 \\
\hline F10 & 0.46 & 0.40 & 0.37 & 0.35 & 0.39 & 0.34 & 0.40 & 0.39 & 0.32 & 0.29 & 0.37 & 4.08 & 8.32 & -0.15 \\
\hline F11 & 0.51 & 0.47 & 0.41 & 0.40 & 0.46 & 0.41 & 0.46 & 0.43 & 0.39 & 0.39 & 0.35 & 4.69 & 9.18 & 0.19 \\
\hline C & 5.37 & 4.81 & 4.33 & 4.26 & 4.69 & 4.20 & 4.69 & 4.94 & 4.32 & 4.23 & 4.50 & & & \\
\hline
\end{tabular}

The final relationships of elements and their average given in the table 3 were calculated and normalized table-to-table in the set is drawn.

Using the MATLAB software, a direct factor $\left(\mathrm{N}(1-\mathrm{N})^{-1}\right)$ has been achieved, $\mathrm{R}$ total Row and $\mathrm{C}$ total Column elements, to get the $\mathrm{R}+\mathrm{C}$ and $\mathrm{R}-\mathrm{C}$ is set. 
Table5: The order of elements influence on each other

\begin{tabular}{|c|c|c|c|c|c|c|c|}
\hline $\begin{array}{c}\text { arrangement } \\
\text { variable }\end{array}$ & $\begin{array}{c}\text { total } \\
\text { row }\end{array}$ & $\begin{array}{c}\text { arrangement } \\
\text { variable }\end{array}$ & $\begin{array}{c}\text { total } \\
\text { column }\end{array}$ & $\begin{array}{c}\text { arrangement } \\
\text { variable }\end{array}$ & $\mathbf{r + c}$ & $\begin{array}{c}\text { arrangement } \\
\text { variable }\end{array}$ & r-c \\
\hline $\mathbf{f 8}$ & 5.6 & $\mathbf{f 1}$ & 5.37 & $\mathbf{f 1}$ & 10.62 & $\mathbf{f 8}$ & 0.68 \\
\hline $\mathbf{f 1}$ & 5.24 & $\mathbf{f 8}$ & 4.93 & $\mathbf{f 8}$ & 10.54 & $\mathbf{f 4}$ & 0.32 \\
\hline $\mathbf{f 5}$ & 4.84 & $\mathbf{f 2}$ & 4.81 & $\mathbf{f 5}$ & 9.53 & $\mathbf{f 1 1}$ & 0.18 \\
\hline $\mathbf{f 1 1}$ & 4.68 & $\mathbf{f 7}$ & 4.6912 & $\mathbf{f 2}$ & 9.46 & $\mathbf{f 5}$ & 0.15 \\
\hline $\mathbf{f 2}$ & 4.64 & $\mathbf{f 5}$ & 4.69 & $\mathbf{f 1 1}$ & 9.18 & $\mathbf{f 6}$ & -0.04 \\
\hline $\mathbf{f 7}$ & 4.47 & $\mathbf{f 1 1}$ & 4.49 & $\mathbf{f 7}$ & 9.14 & $\mathbf{f 1}$ & -0.12 \\
\hline $\mathbf{f 4}$ & 4.58 & $\mathbf{f 3}$ & 4.33 & $\mathbf{f 4}$ & 8.84 & $\mathbf{f 1 0}$ & -0.14 \\
\hline $\mathbf{f 6}$ & 4.15 & $\mathbf{f 9}$ & 4.32 & $\mathbf{f 3}$ & 8.48 & $\mathbf{f 2}$ & -0.16 \\
\hline $\mathbf{f 3}$ & 4.14 & $\mathbf{f 4}$ & 4.25 & $\mathbf{f 6}$ & 8.34 & $\mathbf{f 3}$ & -0.18 \\
\hline $\mathbf{f 1 0}$ & 4.08 & $\mathbf{f 1 0}$ & 4.23 & $\mathbf{f 1 0}$ & 8.31 & $\mathbf{f 7}$ & -0.23 \\
\hline $\mathbf{f 9}$ & 3.88 & $\mathbf{f 6}$ & 4.19 & $\mathbf{f 9}$ & 8.2 & $\mathbf{f 9}$ & -0.44 \\
\hline
\end{tabular}

The final relationships between variables have been prioritized in the above table. It can be concluded that:

F8 element was identified to be the most influential and F1 element as the most effective. Other elements were found to have a partial influence.

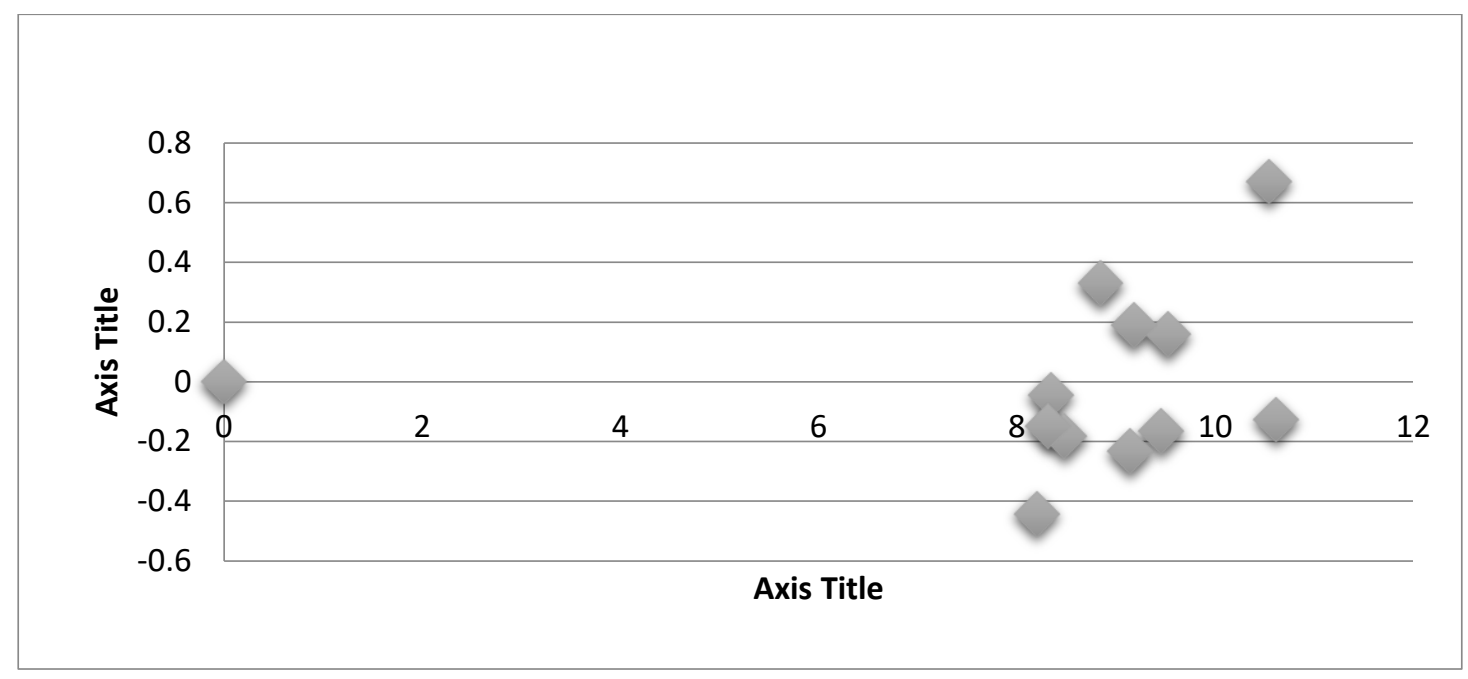

Figure 4: Hierarchy of relations

The final hierarchy of relations, according to the values $(\mathrm{C}-\mathrm{R})$ and $(\mathrm{C}+\mathrm{R})$ is illustrated in the diagram. 


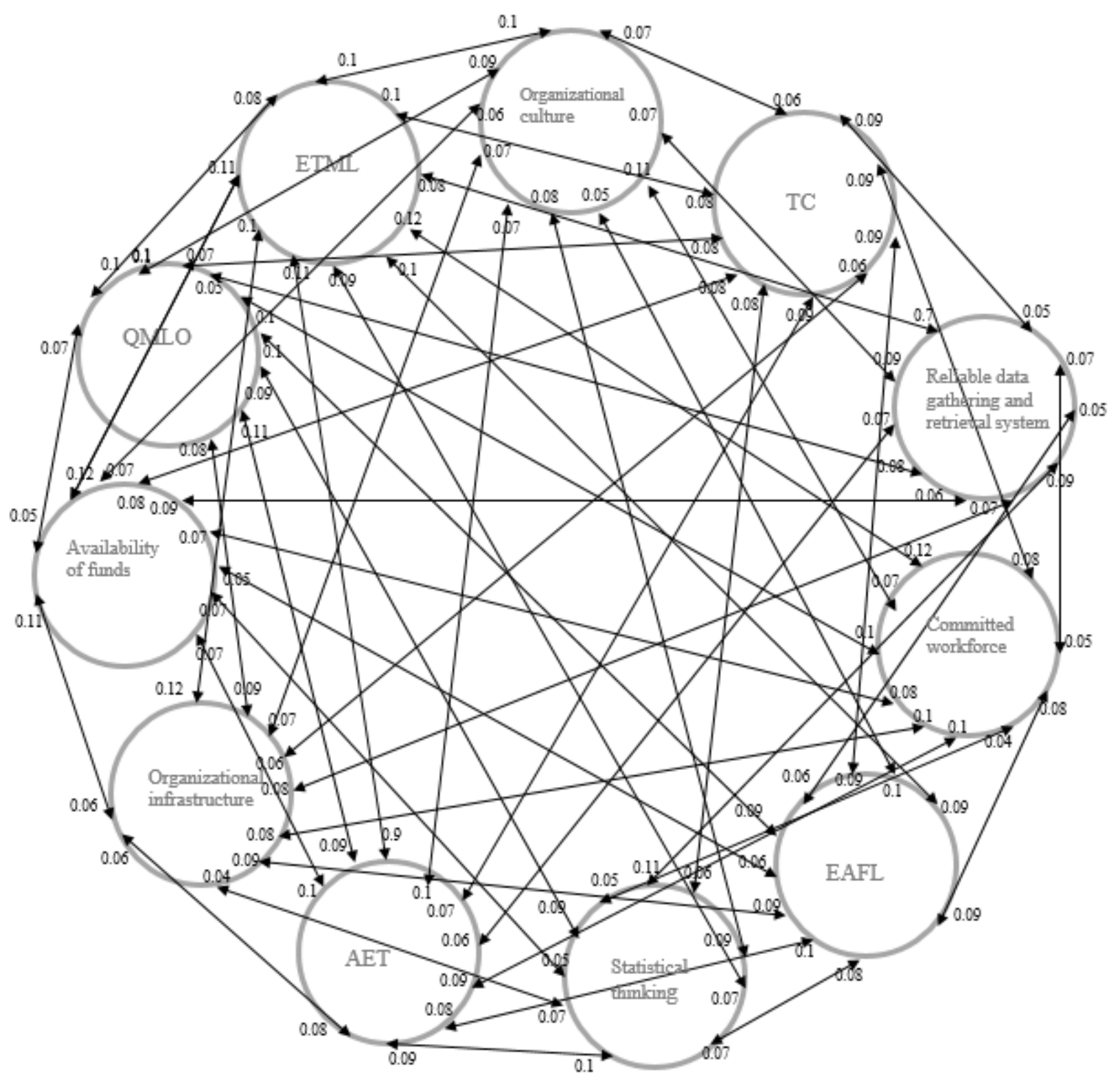

Figure 5: Relative severity of direct and indirect relations algorithms

\section{Conclusions}

Based on the literature survey, 11 enablers of Six Sigma are used; a structured questionnaire is then used to validate the questionnaire. Finally, 11 selected enablers are used to obtain the hierarchy among the enablers. Relationships between 11 variables were measured in this study with DEMATEL technique. Using this technique takes a long time, but it creates a situation which raises the interaction between decision-maker and experts. In this study the relationship between 11 variables were measured. By examining the relationships between these variables employing DEMATEL technique it was found that VariableF1 (Effective Top management leadership role) is known as the effective and F8 (Committed workforce) variable is the most influential. Other elements can be considered as having a partial influence.

The findings of this article are very crucial for industries' professionals, decision makers, consultants and researchers to build Six Sigma competent organization. The paper casts an insight into the enablers of Six Sigma and hierarchy of relationship among them. "ETML role" as indicated by most of the earlier researchers is the key factor for success of Six Sigma; the 
model obtained here also validated the same finding. The implications of these findings entail development of Six Sigma competent organization, setting up time framework to deploy Six Sigma based on organizational developmental capabilities and capacities.

The paper is about a subset of critical success factors known as enablers. Future research can test other factors in addition to factors of the research. There are other multiple attribute decision-making methods such as TOPSIS and VIKOR, which could be applied for ranking the alternatives and it, would be quite interesting to compare the results with the outcomes of the proposed model of this paper.

\section{References}

Ashish Soti, Ravi Shankar, O.P. Kaushal, (2009)," Modeling the enablers of Six Sigma using interpreting structural modeling", Journal of Modeling in Management Vol. 5 No. 2, 2010 pp. 124-141

Amiri Maghsud, SalehiSadaghiyani Jamshid, Payani Nafiseh, Shafieezadeh Mahdi, (2011)," Developing a DEMATEL method to prioritize distribution centers in supply chain",Management Science Letters 1 ,279-288

Andrew Thomas, Richard Barton, Paul Byard. (2008)," METHODOLOGY AND THEORY Developing a Six Sigma maintenance model", Journal ofQuality in Maintenance Engineering" Vol. 14 No. 3, 2008 pp. 262-27

Ben Clegg, Chris Rees, Mike Titchen. (2009)," A study into the effectiveness of quality management training A focus on tools and critical success factors",The TQM Journal Vol. 22 No. 2, 2010 pp. 188-208

Daniel Firka.(2010)," Six Sigma: an evolutionary analysis through case studies", The TQM Journal Vol. 22 No. 4, 2010 pp. 423-434

Diana Heckl, JürgenMoormann, Michael Rosemann.(2010)," Uptake and success factors of Six Sigma in the financial services industry", Business Process Management Journal,Vol. 16 No. 3, 2010. pp. 436-472

Dong-Suk Kim.(2010)," Eliciting success factors of applying Six Sigma in an academic library A case study", Performance Measurement and Metrics, Vol. 11 No. 1, 2010

Gwo-Hshiung Tzeng, Chi-Yo Huang. (2011), "Combined DEMATEL technique with hybrid MCDM methods for creating the aspired intelligent global manufacturing \& logistics systems

Gwo-Hshiung Tzeng, Wen-Hsien Chen, Rachung Yu, Meng-Lin Shih. (2009)," Fuzzy decision maps: a generalization of the DEMATEL methods"

Huang, C. Y., Shyu, J. Z., \& Tzeng, G. H. (2007), "Reconfiguring the innovation policy portfolios for Taiwan's SIP Mall industry”.Technovation, 27(12), 744-765.

Jiju Antony, FrenieJiju Antony, Maneesh Kumar, Byung Rae Cho.(2006)," Six Sigma in service organizations Benefits, challenges and difficulties, common myths, empirical observations and success factors", International Journal of Quality \& Reliability Management, Vol. 24 No. 3, 2007

Jung-Lang Cheng.(2008)," Implementing Six Sigma via TQM improvement: an empirical study in Taiwan", The TQM Journal Vol. 20 No. 3, 2008, pp. 182-195

Kim, W. (2007), Six Sigma Revolution Handbook, Global, Paju. 
K. Jeyaraman, LeamKeeTeo.(2010)," A conceptual framework for critical success factors of lean Six Sigma Implementation on the performance of electronic manufacturing service industry", International Journal of Lean Six SigmaVol. 1 No. 3, 2010 pp. 191-215

Michael Hiete,MirjamMerz, Tina Comes, Frank Schultmann. (2011), "Trapezoidal fuzzy DEMATEL method to analyze and correct for relations between variables in a composite indicator for disaster resilience",

Michael J. Braunscheidel, James W. Hamister, Nallan C. Suresh and Harold Star.(2011)," An institutional theory perspective on Six Sigma adoption", International Journal of Operations \& Production Management Vol. 31 No. 4, 2011 pp. 423-451

Raisinghani, M.S., Ette, H., Pierce, R., Cannon, G. and Daripaly, P. (2005), "Six Sigma: concepts, tools, and applications", Industrial Management \& Data Systems, Vol. 105No. 4, pp. 491-505

Roxana Fekri ,Alireza Aliahmadi , Mohammad Fathian.(2008)," Identifying the cause and effect factors of agile NPD process with fuzzy DEMATEL method: the case of Iranian companies".

Teck-Yong Eng. (2010)," Six Sigma: insights from organizational innovativeness and market orientation", International Journal of Quality \& Reliability Management Vol. 28 No. 3, 2011. pp. 252-262 